\title{
Construction and Thought of the Open Sharing System of Large Instruments in Colleges
}

\author{
Yanping Zhu \\ Jilin Agricultural University, Changchun 130118, China
}

\begin{abstract}
With the continuous development of higher education enterprise and improvement of scientific research conditions, the quality and quantity of large instruments and equipment in colleges and universities have been greatly improved. However, the problem of low efficiency of high quality resources has not been well solved. Problems existed in the construction, management, and utilization of open sharing system of large instruments in colleges are found. In allusion to these problems, the corresponding solutions are doped out. More importantly, it can be used as reference in construction of the opening sharing system of large instruments in other colleges. The practice of opening sharing system of large instruments promotes effective utilization of technological resources in colleges. Making use of advanced technology, intensive operation, humanized service, and networked management will be significant in the construction of a better open sharing system of large instruments in colleges. This paper, taking Harbin Institute of Technology as an example, summarizes the process of its construction of sharing platform of large precise instruments, analyzes the problems in such construction, and eventually finds out some measures to construct the open sharing system of large instruments in colleges.
\end{abstract}

Keywords: open sharing system; large instruments and equipment; technological resources.

\section{Introduction}

As national economy develops rapidly, input in education is increasing gradually. Personnel training, scientific research, and social service are also attached to enough importance in colleges, which has become consensus for teachers and management department in colleges. It not only meet the needs of personnel training, research projects, and social service, but accelerates school-running standards and comprehensive strength [1]. As a consequence, colleges in China pay more attention to large instruments and equipment and the number of such instruments and equipment has increased promptly. However, there are still lots of problems like repeat purchase, disperse putting, enclosed management, little sharing resources, low rate of utilization, and so on.

Hardware facilities like large instruments in colleges are improved in a great degree. Therefore, the issues remained to be dealt with are how to do an effective management of those large instruments, enhance the utilized rate, enlarge the using effectiveness, and how to give full play to the role of large instruments in personnel training, scientific research, and social service [2]. Recent studies focus on the analysis of current situation of large instruments' management and utilization and summary of the unneglectable problems in the construction. This paper, taking the construction of open sharing system of large instruments in Harbin Institute of Technology as an example, specifically analyzes the leaks existed in the construction and comes up with the corresponding solutions so as to get a more effective application of the open sharing system of large instruments in colleges [3].

\section{Common Problems of Large Instruments and Equipment in Colleges}

The construction of large instruments in many colleges solve the problems of poor information-sharing approach, scanty scientific and effective management method, etc. It indeed makes a great influence on promoting and perfecting the sharing system. Whereas, in the meanwhile, some common problems are still remained to be dealt with.

\subsection{Deficiency of Sharing Rate}

At present, open sharing degree of large instruments in the Analysis and Testing Center in colleges is comparatively high, while sharing degree of large instruments separated in the laboratory of other 
faculties is not satisfying. First of all, some large scale equipment, because of its special properties, its versatility is not strong so that it can only be used in the testing and testing of their professional field and narrow in sharing ratio. Second, in colleges, although large equipment open sharing management system has been implemented for many years, shared consciousness of some teachers are still is not strong. This makes sharing rate of those large instruments, especially instruments and equipment with the cost of research purchase on the low side, and fails to show its efficiency in the relevant scientific leading field research and the social service. Once again, in the process of the use of large equipment, quantitative assessment methods of deficient utilization, affect the use of large instrument and equipment. In addition, some large equipment operation and maintenance need to rely on the teacher's scientific research funds to support, but also one of the important reasons for the low sharing rate of large instruments and equipment.

\subsection{Insufficiency of Managing and Technological Personnel}

Modern all kinds of large-scale instruments and equipment are not only large in scale, but also a variety of functions, high degree of integration and specialization. Large scale instruments and have the characteristics of high value and high precision, and complex operation steps, so the work environmental conditions requires high. And according to the different characteristics of the device, it needs for full-time professionals under the large scale to do daily use and maintenance work. Due to the heavy workload of teaching and scientific research, the original staff is often difficult to balance sharing management work of large instruments and equipment. At the same time, the experimental technical personnel has a larger gap compared with scientific research personnel in the title, treatment, promotion and other aspects of teaching. This gap affects the positivity of work of the laboratory technicians on the sharing of large instruments and equipment [4]. The personnel structure of full-time technical and managerial provided for some laboratory equipment lack balance. It can not form a sustainable development of the support force and results in the unbalance of personnel structure. Difficult to have a high efficiency, it fails to form a scientific development, thus restricts the development and utilization of the function of large scale instruments and equipment and influences the improvement of the utilization efficiency of the devices.

\section{Current condition of Large Instruments in Harbin Institute of Technology}

In recent years, Harbin Institute of Technology gives full play to the advantages of interdisciplinary and integration in and form a relatively perfect system of discipline consist of key disciplines, new disciplines and supporting subjects in the process of development and construction of school personnel training, discipline construction and basic research, in which the number of large instruments and equipment providing important support for the teaching and scientific research work grows quickly. From 2008 to 2013 these 6 years, the set number and total price of equipment of large instruments with unit price of more than 200 thousand Yuan increased by 1.92 times and 1.84 times. These large instruments lay a solid foundation for the development of school discipline and talent cultivation. With construction of school "211 Engineering" and "985 project", interdisciplinary research fields continuously expand and penetrate, higher request to large instrument are put forward. Only by expanding sharing service scope can the needs of increasingly development be satisfied [1].

\section{Construct Effective Sharing System of Large Instruments and Equipment}

In order to solve the common problems encountered in the construction of sharing, it is necessary to build effective open sharing incentive and insurance mechanism and a shared platform of large equipment and efficient operation to promote the effective implementation of shared services.

\subsection{Top-level Design, Promote Open Sharing}

College leaders attach great importance to the establishment of the principal charged by the large precision instruments resources open sharing leadership group and overall planning of construction and management of large instrument sharing platform in colleges. Measures to be implemented and organized by laboratory management and teaching conditions. Rearding colleges' development as 
orientation, build a total of large instrument platform and analysis test center, Municipal Environmental Engineering Laboratory Center, Institute of Science Research Center, ect. School open sharing of large instruments set for the implementation of the use of the management approach to the "211 Engineering", "985 Projects" and other special funds for the purchase of equipment must be shared mechanism. Through guiding, coordinating and standardizing the management and utilization of all departments in colleges, optimize the allocation of resources to ensure the sharing of instrument construction to get a sustainable development.

\subsection{Perfect the Evaluation System and Improve the Use Efficiency}

Implementing a guiding policy in the process of construction of large-scale equipment sharing incentive mechanism. Give preferential policies and tilt oblique support in equipment maintenance fees to the outstanding performance of unit on the large equipment design by sharing service work [5]. Fomulate incentive and encouragement measures to stimulate the enthusiasm of the staff at the same time, establish evaluation annual benefit mechanism of nuclear test of large instruments, comprehensively make use of rewards and punishment means to standradize, constrain, and guide the sharing to better develop. At the end of each year, colleges organize expert group to evaluate and assesse the benefit of the large equipment administrator and crew. In accordance with the assessment and evaluation index of the frequency of use, do a comprehensive assessment of the machine of large instrument and equipment utilization, personnel training, scientific research, service income, functional use, development level. Reward the outstandings and reduce funding for those who do not well and adjust the unit by sharing. For the unit of poor examination results in 3 consecutive years, the colleges will be forced to take out of large equipment and redistribute them.

\section{Conclusion}

Large scale instruments is not only an important guarantee for the experimental teaching and scientific research, but a valuable resource for the colleges. Opening sharing system of large instruments is an important way to effectively utilize the scientific and technological resources in colleges. Through the construction of sharing platform of large instruments, certaineffect is gained in the integration of optimization of resource distribution and improvement of sharing system of large instrument equipment. But a lot of difficulties and problems will be encountered in the practice. An important work for colleges is how to use international standard, intensive operation mode, humanized service concept and networked management to do a construction of sharing of large instrument, further perfect the management mechanism of the sharing system, provide all-round, personalized, high level of shared services.

\section{References}

[1] Liang Hong. Practice on Construction of Shared Platform of Large-scale Instruments and Equipment [A]. Laboratory Management and Teaching Condition Security Office, Harbin Institute of Technology, Harbin in 150001, China, 2015(32) 1.

[2] Meng Jianping, Li Shanmei. Exploration on Constructing the Sharing Information Platform of Large-scale Instruments and Equipment in Universities [A]. Guilin University of Technology 541004, China, 2015(5)

[3] CHEN Jing, TANG Feng-chang, KUANG Jian, WANG Jiang-hua. Resource Sharing and Management System of Large-scale Instrument and Equipment [A]. Departments of State Assets and Equipment, China Three Gorges University, Yichang 443002, China, 2013

[4] HUA Xing-xia, WANG Tie-bang, HUANG Wei. Sharing of Large Instruments and Equipment in Colleges and Universities [J]. Office of Laboratory and Facility Management, Nanjing University of Information Science and Technology, Nanjing 210044, China, 2013(5). 
[5] Lin Lei. Implementation of Sharing and Monitoring System of Large-scale Scientific Instrument Based on Delphi [A]. School of Automation Engineering, University of Electronic Science and Technology of China, Chengdu, China, 2011(10)23: 109-112. 